\title{
EMISSIONS, CONCENTRATIONS, \& TEMPERATURE: A TIME SERIES ANALYSIS
}

\author{
ROBERT K. KAUFMANN ${ }^{1}$, HEIKKI KAUPPI ${ }^{2}$ and JAMES H. STOCK ${ }^{3}$ \\ ${ }^{1}$ Center for Energy \& Environmental Studies, Boston University, Boston, MA 02215 \\ E-mail:Kaufmann@bu.edu \\ ${ }^{2}$ Department of Economics, University of Helsinki, P.O. Box 17 (Arkadiankatu 7), \\ FIN-00014, Finland \\ ${ }^{3}$ Kennedy School of Government, Harvard University, Cambridge, MA 02138
}

\begin{abstract}
We use recent advances in time series econometrics to estimate the relation among emissions of $\mathrm{CO}_{2}$ and $\mathrm{CH}_{4}$, the concentration of these gases, and global surface temperature. These models are estimated and specified to answer two questions; (1) does human activity affect global surface temperature and; (2) does global surface temperature affect the atmospheric concentration of carbon dioxide and/or methane. Regression results provide direct evidence for a statistically meaningful relation between radiative forcing and global surface temperature. A simple model based on these results indicates that greenhouse gases and anthropogenic sulfur emissions are largely responsible for the change in temperature over the last 130 years. The regression results also indicate that increases in surface temperature since 1870 have changed the flow of carbon dioxide to and from the atmosphere in a way that increases its atmospheric concentration. Finally, the regression results for methane hint that higher temperatures may increase its atmospheric concentration, but this effect is not estimated precisely.
\end{abstract}

\section{Introduction}

Evidence for the effect of human activity on climate comes from two sources: experiments run by climate models and statistical analyses of historical data. The ability of climate models to simulate the spatial/temporal temperature record is improved by including the radiative forcing of greenhouse gases and tropospheric sulfates (Mitchell and Karoly, 2001; Wigley et al., 1998; Santer et al., 1996; Mitchell et al., 1995). Consistent with these results, statistical analyses indicate that there is a link between surface temperature and the radiative forcing of greenhouse gases and anthropogenic sulfur emissions (Kaufmann and Stern, 1997, 2002; Stern and Kaufmann, 2000; Tol and de Vos, 1998).

The interpretation of statistical results is complicated by stochastic trends in the historical time series, which can generate spurious regression results, and by the possibility that surface temperature and the atmospheric concentrations of $\mathrm{CO}_{2}$ and $\mathrm{CH}_{4}$ are determined jointly, which can generate simultaneous equation bias. Here, we address these potential sources of error by estimating the relationship among anthropogenic emissions of $\mathrm{CO}_{2}$ and $\mathrm{CH}_{4}$, the concentration of these gases, and global surface temperature. To avoid spurious regression results, we use the dynamic ordinary least squares (DOLS) estimator developed by Stock and Watson (1993). 
To avoid simultaneous equation bias, we use an instrumental variables procedure. These techniques are used to estimate equations that are specified to answer two questions; (1) does human activity affect global surface temperature and; (2) does global surface temperature affect the atmospheric concentration of carbon dioxide and/or methane. The results provide direct evidence that since 1870: (1) human activity is largely responsible for the increase in global surface temperature and; (2) higher surface temperature has increased the atmospheric concentration of $\mathrm{CO}_{2}$ and perhaps $\mathrm{CH}_{4}$.

\section{Methodology}

We build a simplified model of the climate system that includes statistically estimated equations for three endogenous variables: global surface temperature and the atmospheric concentrations of $\mathrm{CO}_{2}$ and $\mathrm{CH}_{4}$. Each of these equations specify explanatory variables that include another endogenous variable and variables exogenous to the system (Box 1).

The specifications and techniques that are used to estimate the temperature and concentration equations are determined by the presence of stochastic trends in the data and the possibility that the endogenous variables are determined jointly. Using four test statistics, Stern and Kaufmann (2000) find that the time series for global surface temperature and the radiative forcing of greenhouse gases, anthropogenic sulfur emissions, and solar irradiance contain a stochastic trend. The simplest example of a stochastic trend is a random walk, which is a discrete time version of continuous time Brownian motion, and is given by Equation (1):

$$
Y_{t}=\lambda Y_{t-1}+\varepsilon_{t}
$$

in which the autoregressive coefficient $\lambda=1$, and $\varepsilon$ is a normally distributed random error term (i.e. the innovations) whose mean may be non-zero.

We test the assumption that the time series for emissions and other variables contain a stochastic trend with the augmented Dickey-Fuller (ADF) test (Dickey and Fuller, 1979). To carry out the ADF test, we estimate the following regression for each variable of interest $y$ :

$$
\Delta y_{t}=\alpha+\beta t+\gamma y_{t-1}+\sum_{i=1}^{s} \delta_{i} \Delta y_{t-i}+\varepsilon_{t}
$$

where $\Delta$ is the first difference operator, $t$ is a linear time trend (which is used to represent a possible deterministic trend), $\varepsilon$ is a random error term, and the coefficient $\gamma=\lambda-1$.

The null hypothesis of the ADF test is that the series contains a stochastic trend. The ADF test evaluates this null, $\gamma=0$ i.e. $\lambda=1$, by comparing the $t$-statistic for $\gamma$ against a non-standard distribution (e.g. MacKinnon, 1994). Rejecting the null hypothesis indicates that the autoregressive coefficient $(\lambda)$ is less than one and 
the series is stationary. If this result is obtained for the level of the series, then the series is termed integrated of order $I(0)$. If the ADF statistic does not reject the null hypothesis for the level of the series but rejects the hypothesis for its first difference, the series is said to be integrated of order one $I(1)$ (i.e. it needs to be differenced once to become stationary). Similarly, a series is integrated of order two I(2) if only the second difference of the series is stationary.

The results of the ADF test for the variables in levels in Box 1 fail to reject the hypothesis that the absolute value of the autoregressive coefficient $(\lambda)$ is equal to one (Table I).

Thus, these variables cannot be analyzed as red noise. Instead, the results indicate that the time series for temperature, anthropogenic emissions of $\mathrm{CO}_{2}$ and $\mathrm{CH}_{4}$, and

Box 1

Model Components

\begin{tabular}{|c|c|c|}
\hline Exogenous Variables & Endogenous Variables & Identities \\
\hline $\begin{array}{l}\mathrm{ECO}_{2} \text { Anthropogenic carbon emissions } \\
\text { (Houghton and Hackler, 1999; } \\
\text { Marland and Rotty, 1984) }\end{array}$ & $\begin{array}{l}\text { GLOBL Global Surface } \\
\text { Temperature (Nicholls } \\
\text { et al., 1994; Parker } \\
\text { et al., 1998) }\end{array}$ & $\begin{array}{l}\mathrm{RF} \text { (prefix) Radiative } \\
\text { Forcing } \mathrm{CO}_{2}, \mathrm{CH}_{9}, \\
\mathrm{CFC}_{11}, \mathrm{CFC}_{12}, \mathrm{~N}_{2} \mathrm{O} \\
\text { (Shine et al., 1991; } \\
\text { Kattenberg et al., 1996) }\end{array}$ \\
\hline $\begin{array}{l}\mathrm{ECH}_{4} \text { Anthropogenic methane } \\
\text { emissions (Kaufmann and Stern, } \\
\text { 1996) }\end{array}$ & $\begin{array}{l}\mathrm{CO}_{2} \text { Atmospheric } \\
\text { concentrations (Keeling } \\
\text { and Whorf, 1994; } \\
\text { Etheridge et al., 1996;) }\end{array}$ & $\begin{array}{l}\text { SOX (Wigley and Raper, } \\
\text { 1992) }\end{array}$ \\
\hline $\begin{array}{l}\text { CFC Atmospheric concentration of } \\
\text { CFC's (Prather et al., 1987; Elkins } \\
\text { et al., 1994) }\end{array}$ & $\begin{array}{l}\mathrm{CH}_{4} \text { Atmospheric } \\
\text { concentrations } \\
\text { (Etheridge et al., 1994; } \\
\text { Khalil and Rasmussen, } \\
\text { 1994; Dlugokenchy } \\
\text { et al., 1994) }\end{array}$ & \\
\hline \multicolumn{3}{|l|}{$\begin{array}{l}\mathrm{N}_{2} \mathrm{O} \text { Atmospheric concentration of } \\
\mathrm{N}_{2} \mathrm{O} \text { (Prinn et al., 1990, 1995; } \\
\text { Machida et al., 1995) }\end{array}$} \\
\hline \multicolumn{3}{|l|}{$\begin{array}{l}\text { SOX Anthropogenic sulfur emissions } \\
\text { (ASL, 1997) }\end{array}$} \\
\hline \multicolumn{3}{|l|}{ SUN Solar irradiance (Lean et al., 1995) } \\
\hline \multicolumn{3}{|l|}{$\begin{array}{l}\text { SOI Southern Oscillation Index (Allen } \\
\text { et al., 1991) }\end{array}$} \\
\hline \multicolumn{3}{|l|}{$\begin{array}{l}\text { NAO Northern Atlantic Oscillation } \\
\text { Index (Hurrel, 1995) }\end{array}$} \\
\hline $\begin{array}{l}\text { RFSS Radiative forcing of stratospheric } \\
\text { sulfates in the northern hemisphere } \\
\text { (appendix N) or southern hemisphere } \\
\text { (appendix S) and latitude (appendix) } \\
\text { (Sato et al., 1993) }\end{array}$ & & \\
\hline
\end{tabular}


their atmospheric concentrations contain a stochastic trend. Traditionally, analyses of the temperature record avoid the assumption of stochastic trends because these trends are characterized by their long-term memory - the effects of innovations do not fade over time. As such, temperature would be inherently unstable with no tendency to return to a long-run mean.

This seeming contradiction is reconciled by identifying the sources of the stochastic trends. The stochastic trends in temperature are caused by stochastic trends in the radiative forcings that drive temperature, and not temperature itself. That is, a direct shock to temperature does not accumulate over time. Rather, the stochastic trends in temperature reflect the stochastic trends in the radiative forcing

Table I

Unit Root Tests

Entries are ADF statistics. Sample: 1860-1994

\begin{tabular}{|c|c|c|c|}
\hline Series & $s=2$ & $s=3$ & $s=4$ \\
\hline \multicolumn{4}{|l|}{ I Univariate tests } \\
\hline RFAGG & -1.82 & -1.53 & -1.30 \\
\hline$\triangle$ RFAGG & -6.32 & $-\mathbf{5 . 8 2}$ & -6.32 \\
\hline RFSSS30N30 & -4.43 & -4.09 & -3.61 \\
\hline$\Delta$ RFSSS30N30 & 9.36 & -8.49 & -6.98 \\
\hline $\mathrm{CO} 2$ & $2.36^{\mathrm{a}}$ & 0.70 & 0.54 \\
\hline$\Delta \mathrm{CO} 2$ & $-1.39^{\mathrm{a}}$ & -1.23 & -1.19 \\
\hline$\Delta^{2} \mathrm{CO} 2$ & -9.57 & -7.49 & -6.81 \\
\hline $\mathrm{ECO} 2$ & $0.13^{\mathrm{a}}$ & -0.36 & -0.20 \\
\hline$\triangle \mathrm{ECO} 2$ & -3.78 & -3.55 & -3.26 \\
\hline$\triangle \mathrm{ECO} 2^{\mathrm{b}}$ & -4.83 & -4.73 & -4.51 \\
\hline $\mathrm{CH} 4$ & -0.89 & -0.88 & -0.65 \\
\hline$\Delta \mathrm{CH} 4$ & -6.40 & -5.94 & -4.78 \\
\hline $\mathrm{ECH} 4$ & $1.06^{\mathrm{a}}$ & 0.12 & -0.14 \\
\hline$\triangle \mathrm{ECH} 4$ & -2.68 & -2.24 & -2.09 \\
\hline SOI & -8.25 & -6.95 & -6.09 \\
\hline NAO & -5.89 & -5.30 & -4.51 \\
\hline \multicolumn{4}{|c|}{ II Cointegration tests with estimated coefficients } \\
\hline (GLOBL, RFAGG) & -5.54 & -4.41 & -3.98 \\
\hline$(\mathrm{CO} 2, \mathrm{ECO} 2, \mathrm{GLOBL})$ & -0.12 & -0.17 & -0.53 \\
\hline$(\triangle \mathrm{CO} 2, \mathrm{ECO} 2, \mathrm{GLOBL})$ & -4.41 & -4.14 & -4.21 \\
\hline (CO2-.000469ECO2, GLOBL) & 0.95 & 1.71 & 1.48 \\
\hline$(\Delta \mathrm{CO} 2-.000469 \mathrm{ECO} 2, \mathrm{GLOBL})$ & -3.38 & -3.04 & -2.98 \\
\hline (CH4, ECH4, GLOBL) & -3.98 & -3.64 & -3.53 \\
\hline (CH4-.3517ECH4, GLOBL) & -1.78 & -1.26 & -1.38 \\
\hline
\end{tabular}


Table I

(Continued)

\begin{tabular}{lrrr}
\hline Series & $s=2$ & $s=3$ & $s=4$ \\
\hline III Cointegration tests with imposed coefficients & & & \\
CO2-.000469ECO2 & 2.22 & 0.76 & 0.52 \\
$\Delta \mathrm{CO} 2-.000469 \Delta \mathrm{ECO} 2$ & -1.47 & -1.27 & -1.19 \\
$\Delta \mathrm{CO} 2-.000469 \mathrm{ECO} 2$ & -2.81 & -2.54 & -2.45 \\
$\Delta^{2} \mathrm{CO} 2-.000469 \Delta \mathrm{ECO} 2$ & $-\mathbf{9 . 4 9}$ & $-\mathbf{7 . 5 8}$ & $-\mathbf{6 . 7 5}$ \\
$\mathrm{CH} 4-0.3517 \mathrm{ECH} 4$ & -0.90 & -0.81 & -0.58 \\
$\Delta \mathrm{CH} 4-0.3517 \Delta \mathrm{ECH} 4$ & $\mathbf{- 6 . 7 3}$ & $\mathbf{- 6 . 3 0}$ & $\mathbf{- 5 . 0 2}$ \\
\hline
\end{tabular}

Entries are the ADF test statistics computed using equation (2). Bolded values are significant at the $5 \%$ level (significance level is computed using MacKinnon's (1994) approximation for parts I and III and using Phillips and Ouliaris (1990) critical values for part II). The linear trend term in equation (2) is excluded, if the series is in first difference (except the case denoted by ${ }^{\text {b }}$. Column heading " $s=2$ ", etc., indicates the number of lags used in equation (2).

${ }^{\mathrm{a}} \mathrm{A}$ lag length $s$ is rejected at the $5 \%$ level against the alternative $s+1$.

of greenhouse gases and anthropogenic sulfur emissions. These trends are like "fingerprints" that can be used to identify the effect of radiative forcing on temperature.

Stochastic trends in the radiative forcing data are associated with processes that are driven by human activity and processes by which the atmosphere accumulates gases. Anthropogenic emissions of radiatively active gases are determined by economic activity. The economics literature is replete with studies that indicate GDP and its components contain a stochastic trend therefore, these trends are embodied in emissions. The presence of stochastic trends implies that emissions do not increase as a deterministic function of time (e.g. anthropogenic sulfur emissions decrease sharply after the 1970's due to policies aimed at easing acid deposition and carbon emissions by the Former Soviet Union decline sharply in the 1990's due to economic collapse). Therefore, specifying emissions with a deterministic trend is incorrect. Similarly, the long residence time of many radiatively active gases (e.g. $\mathrm{CO}_{2}, \mathrm{CFC}$ 's) implies that the atmosphere integrates emissions. This can introduce a stochastic trend in the concentration time series, and the corresponding values for radiative forcing. Even if temperature is an inherently stationary series, an autoregressive model that does not control for radiative forcing variables may have unit roots.

The presence of stochastic trends invalidates the blind application of standard statistical techniques such as ordinary least squares (OLS) because they may generate spurious regression results. When evaluated against standard distributions, the correlation coefficients and $t$-statistics for a spurious regression are likely to show that there is a significant relationship between variables when none exists (Granger and Newbold, 1974). The potential for spurious regression results led the IPCC to caution "rigorous statistical tools do not exist to show whether relationships between 
statistically non-stationary data of this kind are truly statistically significant.... (Folland et al., 1992, p. 163)."

At about the same time, time series econometricians developed techniques to analyze relations among integrated time series and thereby avoid spurious regressions. These techniques are based on the principle that if two or more integrated time series have a functionally dependent relation, the stochastic trends present in some of the series also will be present in the others. This shared trend implies that there will be at least one linear combination of the series that is stationary so that there is no stochastic trend in the residual (i.e. the residual is $I(0)$ ). This phenomenon is known as cointegration (Engle and Granger, 1987; for a textbook treatment, see Hamilton, 1994). Kaufmann and Stock (2003) illustrate the notion of spurious regressions and cointegration for carbon cycle data.

Emphasis on cointegration allows us to alleviate some of the difficulties that accompany the statistical analysis of nonstationary time series which contain considerable uncertainty. The uncertainty associated with many of the series in Box 1 has been examined explicitly. Marland and Rotty (1984 find that fossil fuel emissions have an error of about 10 percent after 1950. Before 1950, the error is about 20 percent (Keeling, 1973). Similarly, the temperature data for years after 1900 are more reliable than data for years prior to 1900 (Jones, 1994). Uncertainty in the ice core data for $\mathrm{CO}_{2}$ concentrations is relatively small $1-3$ ppmv (Friedli et al., 1986; Etheridge et al., 1996) but this error is complicated by uncertainty about the date (Craig et al., 1997).

Nonetheless, uncertainty in the time series for $\mathrm{CO}_{2}$ and other variables probably does not have a significant effect on the results reported below. If the uncertainty in the time series is stationary (e.g. white noise), it will not affect tests for cointegration and therefore conclusions about the presence of a statistically meaningful relation among variables. Alternatively, if the data contain systematic errors that are stochastically trending, then we will not find any cointegrating relations in the data because there is no way to eliminate the unobserved stochastic trends associated with the errors. Under these circumstances, stochastically trending errors would obfuscate statistical estimates of physically meaningful relationships rather than create relationships where none exist. Systematic errors will falsely indicate cointegration only if the same systematic error is present in the time series for temperature, concentrations, and emissions. Given the very different methods used to measure and compile the time series for temperature, concentrations, and emissions, it is highly unlikely that these time series contain the same trending errors. Thus, it is unlikely that the relations described below are created by stationary or non-stationary errors in the data.

We estimate the cointegrating relation among integrated variables using Dynamic Ordinary Least Squares, DOLS (Stock and Watson, 1993). DOLS generates asymptotically efficient estimates of the regression coefficients for variables that cointegrate. We use DOLS because it is computationally simple and it performs well relative to other asymptotically efficient estimators (Stock and Watson, 1993). 
The coefficients estimated by DOLS represent the long run relationship among variables. DOLS does not estimate the short-run dynamics as this is not necessary for asymptotically efficient estimation of the cointegrating relation. The short-run responses to deviations from the equilibrium relationship are estimated in a second stage (as described below).

\subsection{TEMPERATURE EQUATION}

The temperature equation has three goals: (1) to estimate the relationship between surface temperature and radiative forcing and the implied temperature sensitivity; (2) to estimate the short-run dynamics by which temperature adjusts to changes in radiative forcing; and (3) to separate the temperature effects of human activity from the temperature effects of natural variability. To achieve these goals, the equation for global surface temperature is estimated in two stages; (1) the cointegrating relation between temperature and radiative forcing and (2) the short run dynamics by which temperature adjusts to changes in radiative forcing and patterns of atmospheric and oceanic circulation. To estimate the cointegrating relation between global surface temperature and radiative forcing, we compile an aggregate for radiative forcing that includes the radiative forcing of greenhouse gases $\left(\mathrm{RFCO}_{2}, \mathrm{RFCH}_{4}, \mathrm{RFCFC} 11\right.$, $\mathrm{RFCFC12}$, and $\mathrm{RFN}_{2} \mathrm{O}$ ), the direct and indirect radiative forcing of anthropogenic sulfur emissions (RFSOX), and the radiative forcing of solar irradiance (RFSUN). This aggregate (RFAGG) includes all components of radiative forcing that contain a stochastic trend (Stern and Kaufmann, 2000). To determine whether there is a statistically meaningful relation between this aggregate and global surface temperature, we test whether these variables cointegrate. Cointegration is determined using OLS to estimate the following equation:

$$
\mathrm{GLOBL}_{t}=\alpha+\beta_{1} \mathrm{RFAGG}_{t}+\mu_{t}
$$

and testing the residual $\left(\mu_{t}\right)$ for a stochastic trend with the ADF statistic (Equation (2)). If the variables cointegrate, the residual will be stationary. The ADF statistic strongly rejects $(P<0.01)$ the null hypothesis that the residual contains a stochastic trend, regardles of the lag length used in Equation (2) (Table I), which indicates that the variables in (3) cointegrate. This result is consistent with cointegration between temperature and radiative forcing found using different techniques (Kaufmann and Stern, 2002). Cointegration indicates that there is a statistically meaningful relation between global surface temperature and radiative forcing that can be estimated efficiently using DOLS. Cointegration also means that this estimate will be efficient even if global surface temperature and radiative forcing are determined jointly.

The DOLS estimate represents the long-run relationship between temperature and radiative forcing. As such, temperature does not adjust immediately to changes in radiative forcing. To simulate the rate at which temperature adjusts to changes in radiative forcing and patterns of atmospheric and oceanic circulation, we estimate 
an error correction model (Engle and Granger, 1987):

$$
\begin{aligned}
\Delta \mathrm{GLOBL}_{t}= & \alpha+\beta_{2} \tilde{\mu}_{t-1}+\sum_{i=1}^{s} \delta_{i} \Delta \mathrm{GLOBL}_{t-i}+\sum_{i=1}^{s} \phi_{i} \Delta \mathrm{RFAGG}_{t-i} \\
& +\sum_{i=0}^{s} \pi_{i} \mathrm{SOI}_{t-i}+\sum_{i=0}^{s} \psi_{i} \mathrm{NAO}_{t-i}+\sum_{i=0}^{s} \zeta_{i} \mathrm{RFSS}_{t-i}+\varepsilon_{t}
\end{aligned}
$$

in which $\tilde{\mu}_{t}$ is the residual from the cointegrating relation estimated by DOLS, SOI is the southern oscillation index, NAO is an index for the North Atlantic Oscillation, and RFSS is the radiative forcing of stratospheric sulfates.

The error correction term $(\theta 2)$ gives the rate at which temperature adjusts to the temperature associated with radiative forcing $\left(\beta_{2}\right)$, short run adjustments to temperature $(\delta)$ radiative forcing $(\phi)$, oceanic and atmospheric circulation $(\pi, \psi)$, and volcanic activity $(\zeta)$. Equation (4) is estimated using OLS because both the residual from the cointegrating relation and the dependent and independent variables are stationary. The two step estimation procedure is justified because the DOLS estimate for the cointegrating coefficient converges to its true value faster than OLS (Stock, 1987; Engle and Granger, 1987).

\subsection{CONCENTRATION EQUATIONS}

Equations for the atmospheric concentration of $\mathrm{CO}_{2}$ and $\mathrm{CH}_{4}$ are derived from an identity that is based on mass balance in the atmosphere;

$$
x_{t}=\rho x_{t-1}+e_{t}+n_{t}
$$

in which $x_{t}$ is the atmospheric concentration at time $t$ and the previous period $x_{t-1}$, $\rho$ is the retention rate, $e_{t}$ denotes net emissions from human sources, and $n_{t}$ denotes net flows from natural (non-human) sources. Ideally, the autoregressive component and emissions from natural sources would be modeled using structural equations. Unfortunately, the mechanisms that control atmospheric retention rates and the net rate of natural emissions are uncertain. For example, scientists cannot balance the flow of carbon to and from the atmosphere due to an unknown sink for carbon (for a short review, see Schimel et al., 2001). Because of the unknown carbon sink and other sources of uncertainty, we approximate natural flows to and from the atmosphere using relatively simple specifications and add complexity (e.g. nonlinearities, structural changes) to evaluate the degree to which the results are robust.

Although Equation (5) specifies concentrations in absolute levels (e.g. ppm), this mass balance assumes that the pre-industrial atmosphere was in equilibrium. At equilibrium, net natural flows to the atmosphere $\left(n_{t}\right)$ equal the losses associated with the retention rate $(1-\rho)$. As the system moves away from equilibrium, changes in temperature and concentrations affect flows to and from the atmosphere. These effects can be differentiated by specifying the retention rate separately from net 
natural flows. The retention rate would be affected most directly by the increase in concentrations relative to the equilibrium. As atmopsheric concentration increases, the net flow of carbon from the atmosphere to the ocean (and perhaps to the terrestrial biota) will increase.

The net effect of temperature on natural flows of carbon to the atmosphere in year $t$ can be approximated (linearly) as follows,

$$
n_{t}=\theta \operatorname{temp}_{t}+v_{t}
$$

where $v_{t}$ represents natural emissions unrelated to temperature. Due to the lack of a structural model, the regression coefficient $\theta$ represents the net effect of several physical mechanisms, some of which may be responsible for the unknown carbon sink. For example, the value of $\theta$ from Equation (6) as used for the $\mathrm{CO}_{2}$ equation represents the net effect of temperature on net primary production, heterotrophic respiration, and/or the solubility of carbon dioxide in sea water.

Representing the net effect of temperature on natural emissions suggests a relatively simple model for atmospheric concentrations by substituting (6) into (5):

$$
x_{t}=\rho x_{t-1}+e_{t}+\theta \text { temp }_{t}+v_{t}
$$

This specification can be simplified for the $\mathrm{CO}_{2}$ equation by collecting the $x$ terms based on the assumption that $\rho$ is one. If $\rho$ is one, emissions, concentrations, and temperature are $I(1)$, and the error is $I(0)$, then (7) is a cointegrating relation. Under these conditions, the concentration equation for $\mathrm{CO}_{2}$ could be estimated using DOLS and cointegration would alleviate concerns about simultaneous equation bias.

Unfortunately, this approach is not possible. As indicated in Table I, emissions, concentrations, and temperature do not cointegrate for either methane or carbon dioxide. The lack of cointegration is not surprising. If unmodeled natural emissions are highly persistent, the error term may be $I(1)$. In the case of $\mathrm{CO}_{2}$, the time series for carbon uptake by the unknown carbon sink that is assembled by Houghton et al. (1998) is $I(1)$ (Kaufmann and Stock, 2003), which implies that $v_{t}$ is $I(1)$. The importance of the unknown carbon sink is indicated by results in Table I, which indicate that $\mathrm{CO}_{2}, \mathrm{ECO}_{2}$, and GLOBL may cointegrate, but this possibility disappears when we impose mass balance by restricting the coefficient associated with $\mathrm{ECO}_{2}$ to 0.000469 , which is the physical constant that translates emissions into concentrations.

To avoid statistical problems associated with the lack of cointegration, we take the first difference of Equation (7)

$$
\Delta x_{t}=\rho \Delta x_{t-1}+\Delta \varepsilon_{t}+\theta \Delta \text { temp }_{t}+\Delta v_{t}
$$

Specifying the concentration equation in first differences eliminates all stochastic trends and therefore allows us to avoid the effects of carbon uptake by the unknown carbon $\operatorname{sink}(\mathrm{s})$ and measurement error on statistical estimates for the effect of temperature on concentrations. 
Equation (8) can be modified to specify the possibility that the atmospheric retention rate $\rho$ depends on state variables. Specifically, saturation effects could lead $\rho$ to depend on the ambient concentration of the gas. For example, higher $\mathrm{CO}_{2}$ concentrations slow oceanic uptake via the Revelle effect, which would increase $\rho$. Alternatively, high concentrations of atmospheric $\mathrm{CO}_{2}$ could increase net primary production via the " $\mathrm{CO}_{2}$ fertilization effect" and thereby increase carbon uptake by terrestrial vegetation. Finally, the retention rate also could depend on temperature. For example, higher temperatures could lengthen the growing season, enhance net primary production, and thereby increase $\mathrm{CO}_{2}$ uptake by terrestrial vegetation.

To account for possible nonlinearities, we let $\rho$ depend on temperature and concentrations. If the nonlinearities in $\rho$ are small, state dependence could be approximated by

$$
\Delta x_{t}=\Delta\left[\rho\left(x_{t-1}, \text { temp }_{t-1}\right) x_{t-1}\right]+\Delta e_{t}+\theta \Delta \text { temp }_{t}+\Delta v_{t} .
$$

For the $\mathrm{CO}_{2}$ equation, we also model $\Delta v_{t}$ (i.e. the net change in natural emissions) as a function of observables $z_{t}$, specifically SOI (Bacastow, 1976), which we can represent as:

$$
\Delta v_{t}=\gamma^{\prime} z_{t}+u_{t},
$$

where $u_{t}$ is an $I(0)$ error term.

Finally, we consider a first order linearization of $\rho$ :

$$
\rho\left(x_{t-1}, \text { temp }_{t-1}^{\prime}\right) \cong \rho_{0}+\rho_{1} x_{t-1}+\rho_{2} \text { temp }_{t-1}
$$

Substituting (10) and (11) into (9) and collecting terms yields,

$$
\begin{aligned}
\Delta x_{t}= & \rho_{0} \Delta x_{t-1}+\rho \Delta\left(x_{t-1}^{2}\right)+\rho_{2} \Delta\left(\operatorname{temp}_{t-1} x_{t-1}\right)+\Delta e_{t}+ \\
& \theta \Delta \operatorname{temp}_{t}+\gamma^{\prime} z_{t}+u_{t} .
\end{aligned}
$$

Physical mechanisms imply that surface temperature and the atmospheric concentration of $\mathrm{CO}_{2}$ and $\mathrm{CH}_{4}$ are determined jointly. For example, temperature appears on the left hand side of the temperature equation (Equation (3)) and appears on the right hand side of the concentration equations (Equations (4) and (5)). This joint determination would cause single equation estimates for the first difference specifications of the concentration equations to suffer from simultaneous equation bias. This bias could cause point estimates for the effect of temperature on the atmospheric concentration of $\mathrm{CO}_{2}$ or $\mathrm{CH}_{4}$ to overstate their true value, regardless of the sample size.

From a statistical perspective, the cause of simultaneous equation bias is correlation between the endogenous variable (temperature) and the error term. To avoid the resultant bias, we use an instrumental variable for temperature when temperature appears on the right hand side of the concentration equations. The use of instrumental variables in the concentration equations can be explained as follows. 
Movements in the atmospheric concentration of carbon dioxide and/or methane are caused by exogenous variables (e.g. anthropogenic emissions), and endogenous variables such as temperature. To obtain an unbiased estimate for the effect of temperature, temperature can be viewed as having two components, an endogenous component, which is associated with changes in $\mathrm{CO}_{2}$ (and $\mathrm{CH}_{4}$ ) concentrations, and an exogenous component. The latter represents changes in temperature due to exogenous variables, such as the radiative forcing of stratospheric sulfates (i.e. volcanic activity) or lagged values of endogenous variables. These variables can be used as instrumental variables because they induce exogenous movements in temperature but do not directly affect the atmospheric concentration of $\mathrm{CO}_{2}$ (or for the methane equation, $\mathrm{CH}_{4}$ ). For example, we use RFSS as an instrument for temperature in the $\mathrm{CO}_{2}$ equation because the radiative forcing of volcanic sulfates affects temperature but volcanic activity can be considered exogenous because any effect on the atmospheric concentration of $\mathrm{CO}_{2}$ is small and occurs much later than its effect on temperature (Krakauer and Randerson, 2003). As such, volcanically induced temperature changes generate changes in $\mathrm{CO}_{2}$ concentrations that can be isolated by using RFSS as an instrumental variable for temperature. Following this approach, the use of instrumental variables "couples" the statistical estimation of the temperature and concentration equations in a way that accounts for the simultaneity among the equations for temperature and concentrations of carbon dioxide and methane.

To use instrumental variables, the effect of temperature on carbon dioxide or methane concentrations is estimated in two stages. In the first stage, temperature is regressed on the instrumental variables. This regression equation is used to generate estimated values for temperature $(\hat{T})$. These estimates are used in place of the observed values for temperature in the second stage regression (i.e. Equation (8)). Both the first and second stage equations can be estimated using ordinary least squares, which is termed the two stage least squares (2SLS) estimator. Alternatively, coefficients can be estimated using the limited information maximum likelihood (LIML) estimator (For a description of the the LIML estimator, see Anderson, 2005; for a textbook treatment of instrumental variables regression, see Wooldridge, 2001). In theory, the LIML and 2SLS estimators are asymptotically equivalent and have the same asymptotic normal distribution.

For the instrumental variables method to yield valid statistical inference, it is required that the instrumental variables must be correlated with the endogenous series. The strength of this correlation is evaluated with an $F$-test on the first stage regression. If the first stage $F$ statistic is less than 10 , then the instruments are "weak" and may generate misleading results because the usual $t$-tests on the second stage regression coefficients are not accurately approximated by a standard normal distribution (Staiger and Stock, 1997). To avoid misleading results, confidence intervals also are estimated by inverting the Anderson-Rubin (Anderson and Rubin, 1949) (AR) test statistic. 


\section{Results}

\subsection{TEMPERATURE EQUATION}

Estimates and summary statistics for five possible specifications of the long-run relationship between temperature and radiative forcing are reported in Table II. In all columns except column 1, the equations are estimated using DOLS. The standard errors, calculated by both the Newey-West and VARHAC ("Vector Autoregressive Heteroskedasticity and Autocorrelation Consistent") procedures, indicate that there is a statistically meaningful relation between global surface temperature and the aggregate radiative forcing variable that includes greenhouse gases, anthropogenic sulfur emissions, and solar irradiance. As described below, this result is not sensitive to the lags/leads used by DOLS or the degree to which the components of radiative forcing are aggregated.

The number of lags and leads used by the DOLS estimator is chosen using the Bayes Information Criterion, BIC (Schwarz, 1978). This criterion indicates that

Table II

Long-run relation between temperature and radiative forcing: Estimation Results for Equation 3

\begin{tabular}{|c|c|c|c|c|c|c|c|}
\hline & (1) & (2) & (3) & (4) & $(5)$ & (6) & (7) \\
\hline $\begin{array}{c}\text { Estimation } \\
\text { method }\end{array}$ & OLS & DOLS (1) & DOLS (2) & DOLS (3) & DOLS (1) & DOLS (1) & DOLS (1) \\
\hline RFAGG & .460 & $\begin{array}{l}.489^{* *} \\
{[.041]} \\
\{.031\}\end{array}$ & $\begin{array}{l}.511^{* *} \\
{[.044]} \\
\{.029\}\end{array}$ & $\begin{array}{l}.539^{* *} \\
{[.044]} \\
\{.027\}\end{array}$ & & $\begin{array}{l}.533^{* *} \\
{[.050]} \\
\{.042\}\end{array}$ & $\begin{array}{l}.428^{* *} \\
{[.057]} \\
\{.055\}\end{array}$ \\
\hline RFCO2 & & & & & $\begin{array}{l}.321 \\
{[.233]}\end{array}$ & & \\
\hline RFCH4 & & & & & $\begin{array}{l}1.92^{* *} \\
{[.74]}\end{array}$ & & \\
\hline RFSOX & & & & & $\begin{array}{l}.945^{* *} \\
{[.236]}\end{array}$ & & \\
\hline RFSUN & & & & & $\begin{array}{l}.563^{* *} \\
{[.243]}\end{array}$ & & \\
\hline Sample & 1860-1994 & 1863-1991 & $1863-1991$ & 1863-1991 & 1863-1991 & 1900-1991 & 1959-1991 \\
\hline
\end{tabular}

Notes : All regressions are run over the indicated sample period, with earlier and later observations as initial/terminal conditions. The BIC for regressions (2), (3), and (4) is $-2.011,-1.947,-1.898$, respectively, so (2) is chosen by BIC. The F-statistic (constructed as the Wald statistic using the Newey-West variance covariance matrix) testing the hypothesis that all the coefficients on the I(1) regressors in $(5)$ are equal is 1.73 ( $p$-value $=.15)$. All regressions include an intercept (not reported). DOLS(p) refers to the Stock-Watson (1993) dynamic OLS estimator with p lags and leads of X, where $\mathrm{X}$ are the $\mathrm{I}(1)$ regressors.

Standard errors: [ ] = Newey-West (4 lags); \{\}$=$ VARHAC (3 lags); ( ) = OLS.

Coefficients are statistically significantly different from zero at the: ${ }^{* *} 1 \%,{ }^{*} 5 \%,+10 \%$ level. 
one lag/lead is optimal (column 2). This choice does not affect the results. The point estimate (and standard error) for the long-run relation between global surface temperature and radiative forcing $\left(\beta_{1}\right)$ changes little if two or three leads/lags are used (compare columns (2), (3), and (4)).

The validity of the confidence interval for $\beta_{1}$ constructed using the estimates and standard errors in Table II depends on radiative forcing having a unit root, that is, $\lambda=1$ in the notation of (1). If $\lambda$ is large but not exactly one, then the confidence intervals can have coverage rates less than the desired 95\%, e.g. Kauppi (2004). Moreover, the methods used here are all based on asymptotic theory, which might not provide a good approximation for our sample size of 135. At the suggestion of a referee, we therefore conducted a Monte Carlo study in which 135 pairs of artificial data on (GLOBL, RFAGG) were generated according to the estimated DOLS equation (Table II, Equation (2)), with auxiliary third order autoregressions for the system errors, in which the largest autoregressive root of RFAGG was varied through its $95 \%$ confidence interval of $(0.942,1.035)$. The cointegrating coefficient and its standard error were then estimated using DOLS (exactly as in Table II) for 10000 replications of these artificial data. The results indicate a finite-sample downward bias of the standard errors of approximately $10 \%$. For $\lambda=0.942$, the asymptotic $95 \%$ confidence interval has an actual finite-sample coverage rate of $88 \%$; for $\lambda=1.035$, the coverage rate falls to $69 \%$. These results suggest caution in interpreting the standard errors on RFAGG in Table II, so in our subsequent analysis we use the more conservative Newey-West standard errors for the cointegrating coefficient $\beta_{1}$.

Consistent with physical theory, the aggregate for radiative forcing is based on the assumption that the temperature effect of a unit of radiative forcing (e.g. $\mathrm{W} / \mathrm{m}^{2}$ ) is equal across forcings. To test this assumption, we estimate a specification that disaggregates the components of radiative forcing. Consistent with statistical expectations, individual coefficients are estimated imprecisely (column 5). The hypothesis of coefficient equality is not rejected at the $10 \%$ level $(F(4,108)=$ 1.73 , using the Newey and West (1987) covariance matrix, which adjusts for serial correlation in the error term (under the maintained assumption of cointegration, this has an asymptotic distribution which is chi-squared with four degrees of freedom, divided by 4). Together, these results suggest that the results reported in column 2 provide the most parsimonious representation of the long-run relation between temperature and radiative forcing.

The results of the error correction model indicate that temperature adjusts to deviations from the long run equilibrium relation between temperature and radiative forcing. The estimate of the regression coefficient $\beta_{2}$ associated with the lagged residual from the cointegrating relation indicates that about 58 percent of the disequilibrium in the cointegrating relation between temperature and radiative forcing is eliminated per year. This rate is similar to the estimate by Kaufmann and Stern (2002). On the other hand, there is no evidence that temperature adjusts to lagged first differences of temperature and radiative forcing (Table III). These 
results are unaffected by the presence of changes in atmospheric and oceanic circulation and volcanic activity (columns 3-4) or the number of lags and leads used by the DOLS estimator (columns 5-6).

Regression results for Equation (4) also show the statistically significant effects of the radiative forcing of stratospheric sulfates, the southern oscillation, and the North Atlantic oscillation. Consistent with previous results, decreases in the SOI increase global surface temperature (ENSO events raise temperature) while stratospheric sulfates have a negative effect on surface temperature. The coefficient associated with stratospheric sulfates is considerably smaller than that associated with the aggregate for radiative forcing. This may be caused by the difficulty associated with estimating temperature sensitivity from volcanic forcing. Using simple energy balance models, Lindzen and Giannitsis (1998) demonstrate that large changes in the parameter for temperature sensitivity have a small impact on the simulated temperature effect of volcanic activity. For example, the peak temperature effect increases only $0.15^{\circ} \mathrm{C}$ as temperature sensitivity increases from 0.6 to $4.0^{\circ} \mathrm{C}$ (Lindzen and Giannitsis, 1998). We explore this uncertainty by using the temperature equation to simulate the temperature effect of the 1991 eruption by Mt. Pinatubo (see Simulation Analysis).

The negative sign associated with the variables for NAO contradicts the positive temperature effect described by Hurrell (1996). This difference may be caused by the NAO index used (Ponta Delgada, Azores minus Iceland versus Lisbon minus Iceland), the use of global surface temperature instead of temperature between $20^{\circ} \mathrm{N}$ and $90^{\circ} \mathrm{N}$, and/or the use of annual averages for temperature and the NAO index versus winter values. For example, the statistical significance of the NAO index drops when we use an NAO index that measures the pressure difference between Lisbon and Iceland (column 8, Table III). Consistent with this sensitivity, we do not attach much significance to the coefficients associated with the North Atlantic Oscillation.

\subsection{CARBON DIOXIDE EQUATION}

The small $F$ statistics for the first stage regressions indicate that the instruments for temperature are weak. The effect of this weakness is evaluated by using 2SLS and LIML techniques to estimate a linear version of Equation (11). A comparison of columns (1) and (2) of Table IV indicates that the 2SLS and LIML point estimates and standard errors are quite similar. Subsequent specifications are estimated using LIML because LIML point estimates and confidence intervals are more reliable than their 2SLS counterparts when the instruments are weak (Staiger and Stock, 1997).

Regression results from nearly all specifications indicate that the change in the atmospheric concentration of $\mathrm{CO}_{2}$ is related to global surface temperature (Table IV). As such, these results provide direct evidence that temperature increases since 1870 have on net, increased the atmospheric concentration of $\mathrm{CO}_{2}$. The positive 


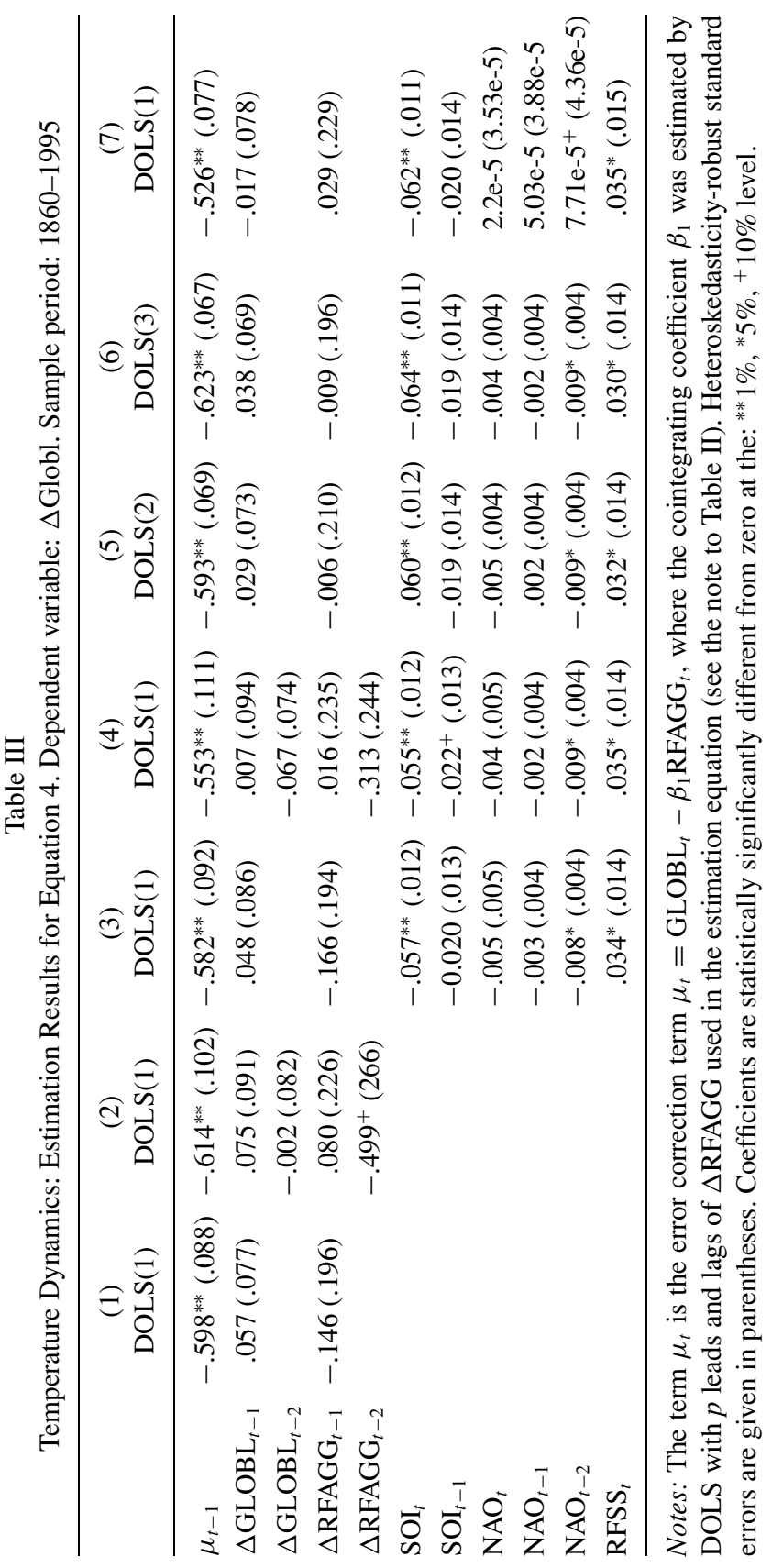


R. K. KAUFMANN ET AL.

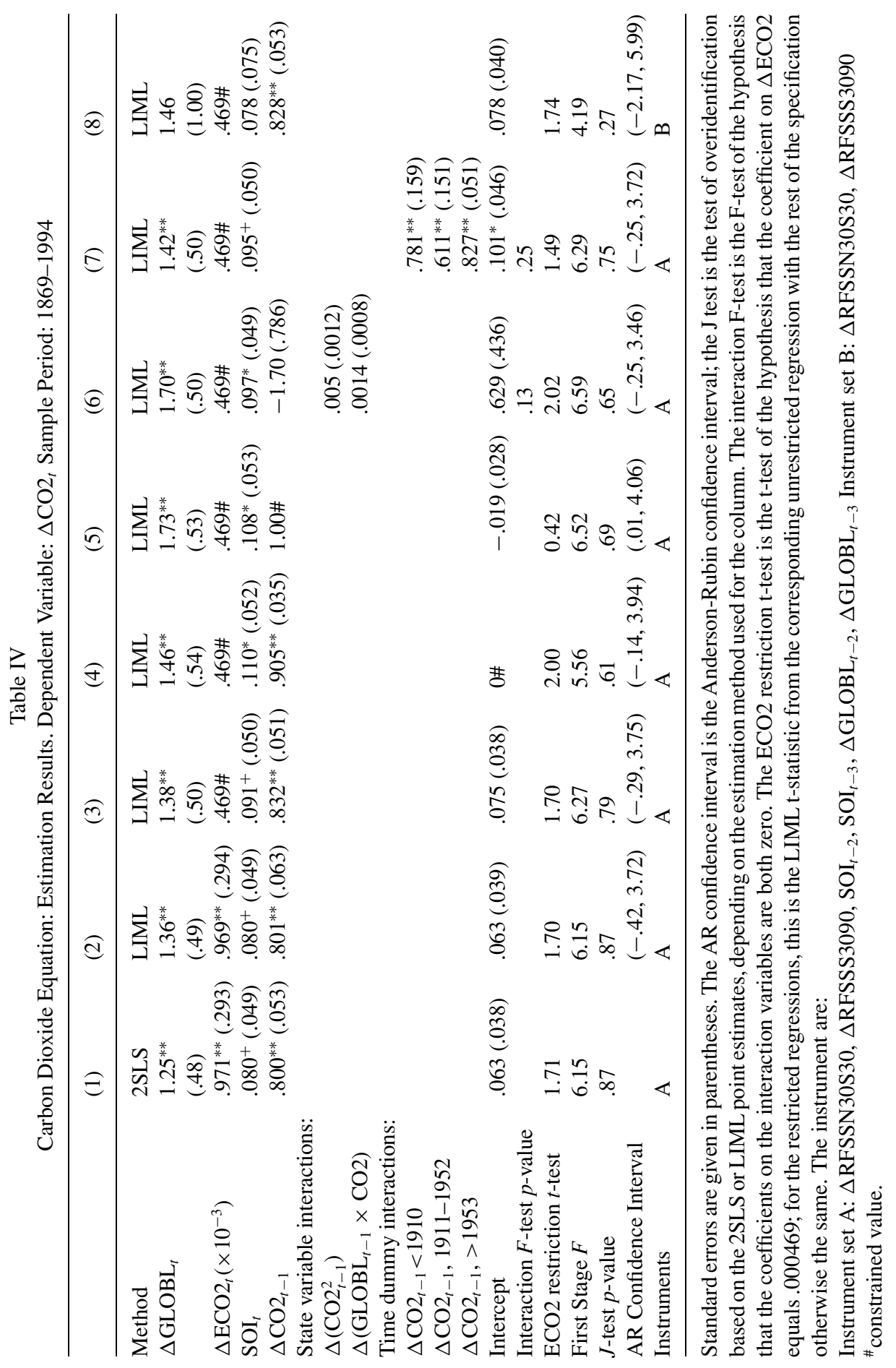


effect may represent several physical mechanisms, such as a reduction in the ocean's ability to absorb carbon (Macintyre, 1978), changes in upwelling that slow the flow of carbon from the ocean to the atmosphere (Dettinger and Ghil, 1998), and/or an increase in heterotrophic respiration relative to net primary production (Vukicevic et al., 2001). The regression coefficients indicate that a $1{ }^{\circ} \mathrm{C}$ rise in temperature increases the atmospheric concentration of $\mathrm{CO}_{2}$ by about $1.5 \mathrm{ppmv}$. Although this effect does not reflect any single physical mechanism, the magnitude of this net effect is similar with a theoretical analysis of the ocean's ability to absorb $\mathrm{CO}_{2}$, which indicates that a $1{ }^{\circ} \mathrm{C}$ rise in ocean surface temperature (100m surface layer) would increase the atmospheric concentration of $\mathrm{CO}_{2}$ by $1.5 \mathrm{ppm}$ (Macintyre, 1978). The regression coefficient also is the same order of magnitude of an empirical estimate that suggests $\mathrm{CO}_{2}$ concentrations rise by about 3 ppmv per $1{ }^{\circ} \mathrm{C}$ (Keeling et al., 1989).

Despite the consistency of the temperature effect, the regression coefficients associated with concentrations and emissions reflect the inability to balance carbon flows in and out of the atmosphere due to the unknown carbon sink. Mass balance in Equation (5) implies that there is a unit coefficient on human emissions and no intercept. A unit coefficient on $e_{t}$ in Equation (5) corresponds to the restriction that the coefficient associated with $\triangle \mathrm{ECO}_{2}$ is 0.000469 , which is the conversion factor that translates a mass of $\mathrm{CO}_{2}$ (thousand petagrams) into its atmospheric concentration (ppmv). Although the estimated coefficient is twice this, this estimate is imprecise and the hypothesis that the coefficient on $\triangle \mathrm{ECO}_{2}$ equals its theoretical value is not rejected at the $5 \%$ level in specifications (1)-(3). To compensate for this large value, the statistical technique assigns a low value to $\rho$. This combination of values "solves" the difficulties associated with the unknown carbon sink by putting extra of carbon into the atmosphere and then taking it out quickly. In column 3, we ensure mass balance by imposing a value of 0.000469 on the coefficient associated with $\Delta \mathrm{ECO}_{2}$. The value of $\rho$ rises slightly and the intercept becomes statistically significant $(p<0.05)$. Taken literally, this intercept increases the atmospheric concentration of $\mathrm{CO}_{2}$ by $0.075 \mathrm{ppmv}$ annually. This secular increase is nonsensical and so we suppress the constant and impose mass balance on emissions in specification (5). Together, these restrictions are inconsistent with the inability to balance the global carbon cycle due to the unknown carbon sink, therefore the mass balance restriction on the coefficient associated with $\Delta \mathrm{ECO}_{2}$ is rejected $(p<0.05)$.

Statistical estimates for $\rho$ are substantially lower (i.e. shorter residence time) than implied by the physical science evidence. This result reflects inadequacies in existing statistical techniques. Estimators of autoregressive coefficients are biased towards zero (Hamilton, 1994), and this bias is especially pronounced when the true autoregressive coefficient is large (i.e. when $\rho$ is close to 1 ). This bias increases when a constant is included, and this makes the estimated value for $\rho$ smaller in specification (3) than in (4). This bias can be eliminated in simple models but to the best of our knowledge, methods that can adjust for this bias have not been developed for the type of models estimated here, in which there are additional regressors and the estimation procedure uses instrumental variables methods. 
To evaluate the effect of this bias on the statistical estimates for the temperature effect, we impose different values on $\rho$. As an extreme case, in which there is no net flow of carbon from the atmosphere, we impose $\rho=1$. This extreme assumption does not materially alter the estimated coefficients on the other variables. Nor can we reject a specification that imposes a value of 0.965 for $\rho$, which is the value obtained by OLS estimation of Equation (7) in levels when we impose the mass balance conversion coefficient 0.000469 on $\mathrm{ECO}_{2}$. Such a value for $\rho$ is consistent with the long persistence of a one-time pulse of carbon indicated by models that simulate the physical mechanisms that determine the rate of carbon flows to and from the atmosphere (Albritton and Filho, 2001). Based on these results, we conclude that the relatively low point estimate of $\rho$ in specifications (1)-(3) is caused by non-normal and biased estimator distributions. As a result, we cannot use the estimates of $\rho$ to make statements about the size of the $\mathrm{CO}_{2}$ fertilization effect, the Revelle effect, or any other physical mechanism by which the atmospheric concentration of $\mathrm{CO}_{2}$ may affect the rate of which carbon flows to or from the atmosphere. Nonetheless, these difficulties do not affect the estimates of the other coefficients, most importantly the effect of temperature on the atmospheric concentration of $\mathrm{CO}_{2}$.

Despite uncertainty about the value of $\rho$, there is little statistical evidence that $\rho$ is state dependent. The nonlinear terms in column 6 are jointly insignificant at the $10 \%$ level, although the temperature-concentration term is significant at the $10 \%$ (but not $5 \%$ level). Regression results from a specification that represents the possibility that the removal rate changes over time show no marked trend (specification 7), and the null hypothesis that $\rho$ is constant cannot be rejected $(p>0.25)$.

Specification (8) considers a reduced instrument list, which includes the radiative forcing of stratospheric sulfates only. We drop lags of $\triangle$ GLOBL and SOI because they may be correlated with a serially correlated error term. Without lags of $\triangle$ GLOBL and SOI, the first stage $F$ statistic drops to 4.19 , and the estimates are considerably less precise. Nonetheless, the point estimates are similar to those in column (3), which suggests that the conclusion that temperature affects the flow of carbon to and from the atmosphere is not sensitive to the instrument set.

\subsection{METHANE EQUATION}

The mass balance equation seems inconsistent with the time series properties of methane concentrations, which appear to be $I(1)$, and anthropogenic emissions, which appear to be $I(2)$. The seeming contradiction can be reconciled by the magnitude of anthropogenic emissions and the physical determinants of atmospheric methane concentrations. In any year, anthropogenic methane emissions are a relatively small component of atmospheric concentrations, which implies that the $I(2)$ component of atmospheric concentrations is small. Furthermore, the atmospheric lifetime of methane is relatively short (the autoregressive coefficient is 
significantly less than 1.0) which would tend to "erase" the $I(2)$ trend in methane emissions. Together, these two factors make it difficult to detect the $I(2)$ trend in the concentration data, therefore $\mathrm{CH}_{4}$ appears to be $I(1)$. Because of this ambiguity, we examine the time series properties of $\mathrm{CH}_{4}-0.3517 \times \mathrm{ECH}_{4}(0.3517$ is the conversion factor that translates teragrams of $\mathrm{CH}_{4}$ to ppbv). As indicated in Table I, this constructed series is $I(1)$. This is consistent with a retention rate $(\rho)$ substantially less than one, GLOBL being $I(1)$, and an error term that is either $I(0)$ or $I(1)$. A value of $\rho$ substantially less than one is consistent with the short residence time of methane (about a decade) relative to carbon dioxide.

The first stage $F$ for the $\mathrm{CH}_{4}$ equation is somewhat larger than for the $\mathrm{CO}_{2}$ equation, and the LIML and 2SLS results are quite similar (Table V). None of the specifications are rejected by the overidentification J-test, and all of the AR confidence intervals for the coefficient on $\triangle$ GLOBL are nonempty. The AR confidence intervals generally are similar to, but somewhat wider than, the LIML confidence intervals.

For all specifications, the point estimates for the effect of global surface temperature on methane concentrations are similar (Table V). Despite this similarity, these estimates are imprecise. The hypothesis that the coefficient on $\triangle$ GLOBL is zero cannot be rejected at the $10 \%$ level using the LIML estimates, and the AR confidence intervals for this coefficient all include zero. Together, these results indicate that we cannot estimate the effect of global surface temperature on the atmospheric concentration of methane in a statistically precise manner.

Estimation results for specifications (1)-(3) are consistent with mass balance. Although the point estimate of the coefficient on $\triangle \mathrm{ECH}_{4}$ is almost three times its theoretical value 0.3517 , this estimate is very imprecise and the hypothesis that it equals its theoretical value is not rejected at the $10 \%$ level. Similarly, the intercepts in specifications (1) and (2) are not statistically different from zero at the $10 \%$ level. Finally, the estimates for $\rho$ vary between 0.35 and 0.44 . These values are significantly less than 1.0 , which is consistent with physical theory. On the other hand, the values imply a residence time that is shorter than the 8.4 year atmospheric residence time and the 12 year perturbation time reported in the literature (Ehhalt and Prather, 2001).

The physical mechanisms that remove methane from the atmosphere imply that $\rho$ is not constant, but results that indicate $\rho$ is not constant probably are statistically spurious artifacts because they contradict physical theory. The only statistically significant nonlinear effect in specification (4) is the concentration term. The negative sign on this term corresponds to an inverse saturation effect (i.e. a smaller value of $\rho$ at higher concentrations). Moreover, estimates for the interaction terms in specification (5) suggest that the removal rate increases from 37\% (1-0.629) in the first third of the sample to $78 \%(1-0.217)$ in the final third. There is no physical reason to believe that the direction or magnitude of this change is plausible. Instead, this pattern of time varying persistence may be caused by changes in the data. Concentration data change smoothly early in the sample period when values are derived from ice cores, as opposed to sharp changes during the observational 


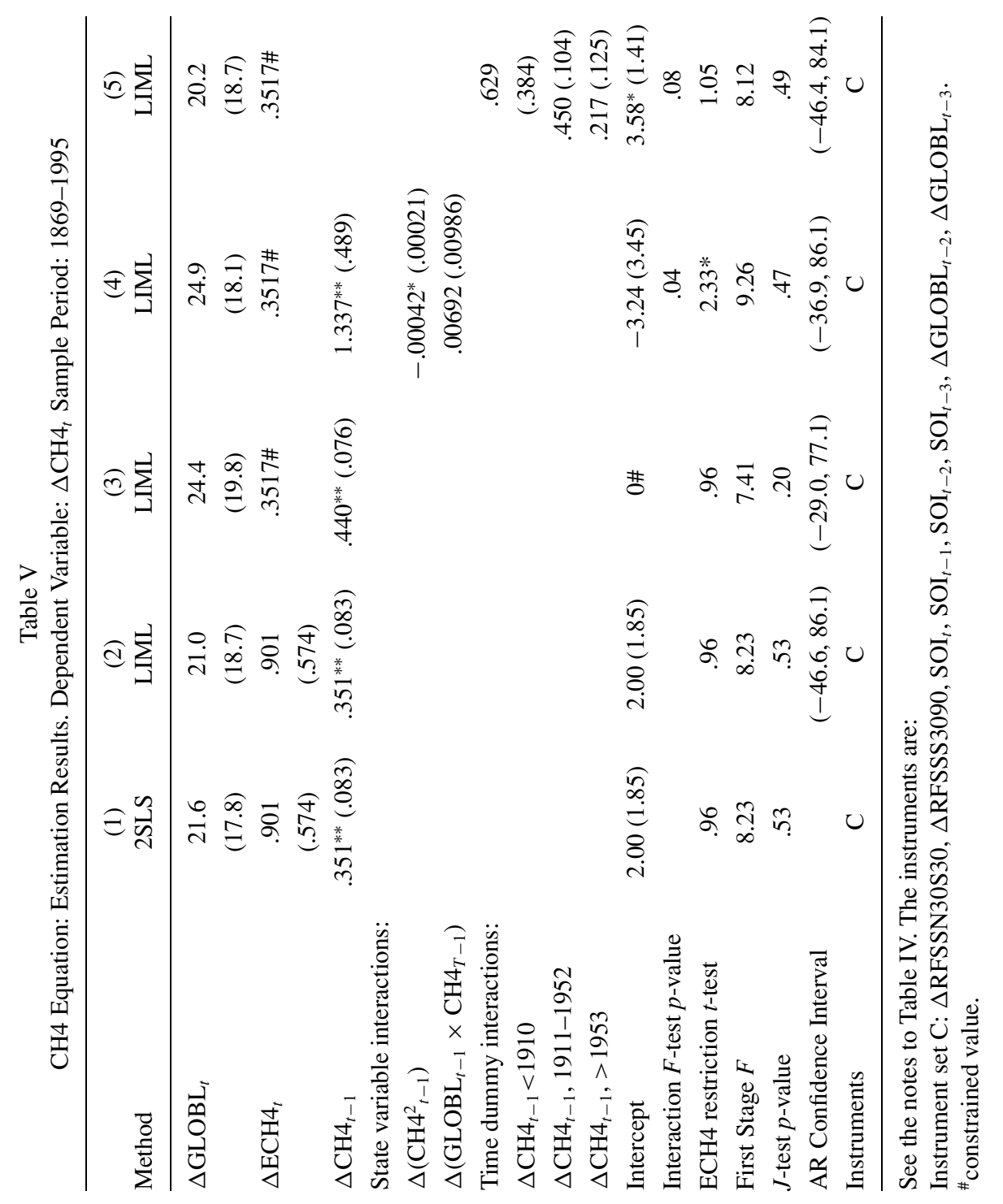


record. Smoothness will increase the estimates for persistence, which will increase $\rho$ early in the sample.

As a final diagnostic, the residuals from the three equations are modeled using a second order vector autoregression. There is a small but nonzero serial correlation in each equation, which is consistent with unmodeled nonlinearities and omitted serially correlated influences on net natural emissions. However, there is no cross correlation $(p>0.15)$, which suggests that these omitted variables do not mask some remaining simultaneity that is not modeled explicitly.

\section{Simulation Analysis}

We assemble the four endogenous equations with the identities to generate a simple simultaneous equation model as follows:

Endogenous equations

$$
\begin{aligned}
\mathrm{GLOBL}_{t}= & 0.489 \mathrm{RFAGG}_{t} \\
\Delta \mathrm{GLOBL}_{t}= & -0.582\left(\mathrm{GLOBL}_{t-1}-0.489 \mathrm{RFAGG}_{t-1}\right)+0.034 \mathrm{RFSS}_{t} \\
& +0.047 \Delta \mathrm{GLOBL}_{t-1}-0.166 \Delta \mathrm{RFAGG}_{t-1}-0.057 \mathrm{SOI}_{t} \\
& -0.020 \mathrm{SOI}_{t-1}-0.005 \mathrm{NAO}_{t}-0.003 \mathrm{NAO}_{t-1}-0.008 \mathrm{NAO}_{t-2}
\end{aligned}
$$

$$
\begin{aligned}
\Delta \mathrm{CO}_{2 t}= & 0.000469 \Delta \mathrm{ECO}_{2 t}+1.46 \Delta \mathrm{GLOBL}_{t-1}+0.110 \mathrm{SOI}_{t-1} \\
& +0.905 \Delta \mathrm{CO}_{2 t-1} \\
\Delta \mathrm{CH}_{4 t}= & 0.3517 \mathrm{ECH}_{4 t}+24.4 \Delta \mathrm{GLOBL}_{t-1}+0.44 \Delta C H_{4 t-1}
\end{aligned}
$$

Identities

$$
\begin{aligned}
& \mathrm{GLOBL}_{t}=\mathrm{GLOBL}_{t-1}+\Delta \mathrm{GLOBL}_{t} \\
& \mathrm{CO}_{2 t}=\mathrm{CO}_{2 t-1}+\Delta \mathrm{CO}_{2 t} \\
& \mathrm{CH}_{4 t}=\mathrm{CH}_{4 t-1}+\Delta \mathrm{CH}_{4 t} \\
& \mathrm{RFCO}_{2 t}=6.3 \ln \left(\mathrm{CO}_{2 t} / \mathrm{CO}_{2} 1860\right) \\
& \mathrm{RFCH}_{4}=0.03873\left(\sqrt{\mathrm{CH}_{4 t}}-\sqrt{\mathrm{CH}_{41860}}\right)
\end{aligned}
$$

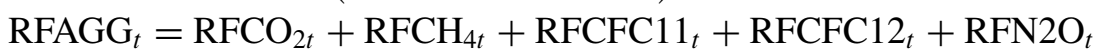

$$
\begin{aligned}
& +\mathrm{SOX}_{t}+\mathrm{RFSUN}_{t}
\end{aligned}
$$

Exogenous variables

\section{RFCFC11, RFCFC12, RFN2O, RFSUN, SOX, ECO2, ECH4}

in which parameters are taken from the following estimation results [Equation (13) Table II specification (2); Equation (14), Table III specification (3); Equation (15) 
Table IV specification (4); Equation (16) Table V specification (3). In this section, we use this model to: (1) separate the effects of natural variability and human activity on global surface temperature between 1870 and 1990; (2) estimate the effect of exogenous variables on temperature and concentrations of atmospheric $\mathrm{CO}_{2}$, and (3) evaluate temperature sensitivity and climate dynamics.

\subsection{THE TEMPERATURE EFFECT OF NATURAL VARIABILITY VERSUS HUMAN ACTIVITY}

To separate the temperature effect of human activity from natural variability, we simulate the simple climate model given by Equations (13)-(22) with either human activity or natural variability held constant. To assess the effect of natural variability, we hold human activity constant by setting anthropogenic emissions of $\mathrm{CO}_{2}, \mathrm{CH}_{4}$, and sulfur to zero, set the concentration of $\mathrm{CO}_{2}, \mathrm{CH}_{4}, \mathrm{CFC} 11, \mathrm{CFC12}$, and $\mathrm{N}_{2} \mathrm{O}$ to their 1870 level, and simulate the model with the historical pattern of changes in SUN, RFSS, SOI, and NAO. Changes in these variables cause a great deal of variability, but do not cause global surface temperature to increase significantly (Figure 1).

To asses the effect of human activity, we eliminate the effects of natural variability. We do so by holding SUN, RFSS, SOI, and NAO at their 1870 level. To

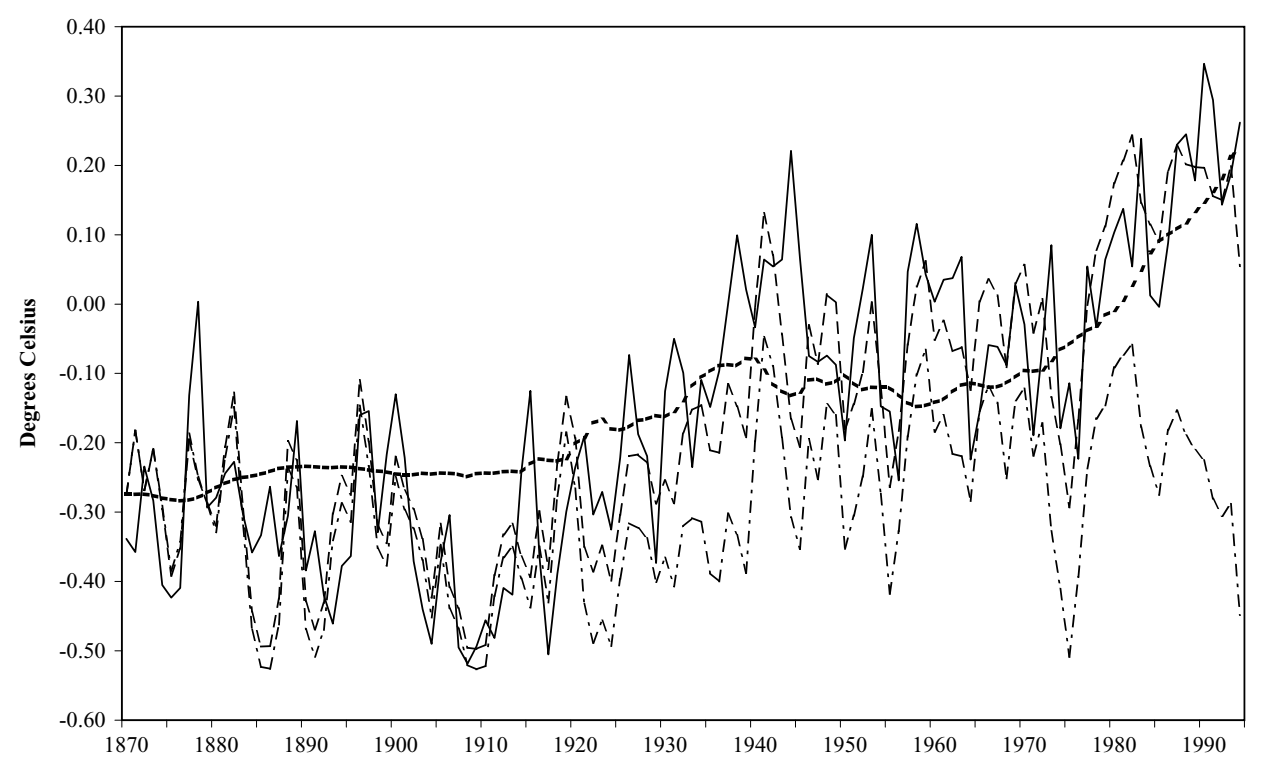

Figure 1. Historical temperature (solid line), temperature simulation based on changes in natural forces (RFSUN, RFSS, SOI, and NAO-dashed-dotted line), temperature simulation based on changes in radiative forcing associated with human activity $\left(\mathrm{RFCO}_{2}, \mathrm{RFCH}_{4}, \mathrm{RFCFC} 11, \mathrm{RFCFC12}, \mathrm{RFN}_{2} \mathrm{O}\right.$, RFSOX - dotted line), temperature simulation based on both natural factors and radiatively active gases associated with human activity (dashed line). 
avoid the disruptive effect of the unknown carbon sink and the relatively short residence time for methane on the model's ability to simulate the temperature effect associated with anthropogenic emissions of $\mathrm{CO}_{2}$ and $\mathrm{CH}_{4}$, we set their concentrations exogenously consistent with their historical values (rather than use Equations (15) and (16)). The concentrations of CFC11, CFC12, and $\mathrm{N}_{2} \mathrm{O}$ also follow their historical values.

Simulation results indicate that changes in the atmospheric concentration of greenhouse gases and anthropogenic sulfur emissions account for much of the increase in global temperature between 1870 and 1990 (Figure 1). This increase is not steady. Temperature increases between 1910 and 1944 and from 1970 to 1990 are associated with increases in total radiative forcing. These increases are associated with an increase in the radiative forcing of greenhouse gases relative to anthropogenic sulfur emissions. The radiative forcing of anthropogenic sulfur emissions increases at about the same rate as greenhouse gases between 1944 and 1976. As a result, there is relatively little net increase/decrease in total radiative forcing and therefore, global surface temperature. The timing of these temperature effects is consistent with results obtained from model simulations (Andronova and Schlesinger, 2000; Tett et al., 1999). Finally, an experiment that simulates the historical changes in both natural variables and gases associated with human activity is able to account for much of variation in global temperature over the last 130 years (Figure 1).

\subsection{THE EFFECT OF EXOGENOUS VARIABLES}

The effect of exogenous variables on temperature and concentrations can be assessed by using the model to simulate impulse response functions. To run these experiments, we set exogenous variables to their pre-industrial value (e.g. zero emissions of $\mathrm{CO}_{2}, \mathrm{CH}_{4}$, and sulfur) or zero (e.g. SOI, NAO, RFSS), use a version of the $\mathrm{CO}_{2}$ equation that suppresses the constant (specification 3), and allow the system to come to equilibrium. We simulate a series of experiments in which this equilibrium is perturbed by a one-time increase in $\mathrm{CO}_{2}$ or $\mathrm{CH}_{4}$ emissions $(9.6 \mathrm{Pg}$. and $580 \mathrm{Tg}$. respectively) that generates an immediate $0.1 \mathrm{~W} \mathrm{~m}^{-2}$ increase in radiative forcing (the $\mathrm{CO}_{2}$ and $\mathrm{CH}_{4}$ experiment respectively), a one-time $0.1 \mathrm{~W} \mathrm{~m}^{-2}$ increase in the radiative forcing of solar irradiance (sun experiment), a two year decrease in the SOI that mimics the 1982-1983 El Niño (ENSO experiment), and a three year change in RFSS that mimics the eruption of Mount Pinatubo (Pinatubo experiment).

Consistent with the equal impact of across forcings, the one-time increase in $\mathrm{CO}_{2}$ emissions, $\mathrm{CH}_{4}$ emissions, or solar irradiance has the same effect on temperature in the short run (Figure 2). The long-run effect of these changes varies by forcing. Consistent with our argument that temperature itself is not $I(1)$, the increase in solar activity has little effect beyond the first year. The temperature effect of the one-time increase in $\mathrm{CH}_{4}$ emissions is slightly longer due to the 


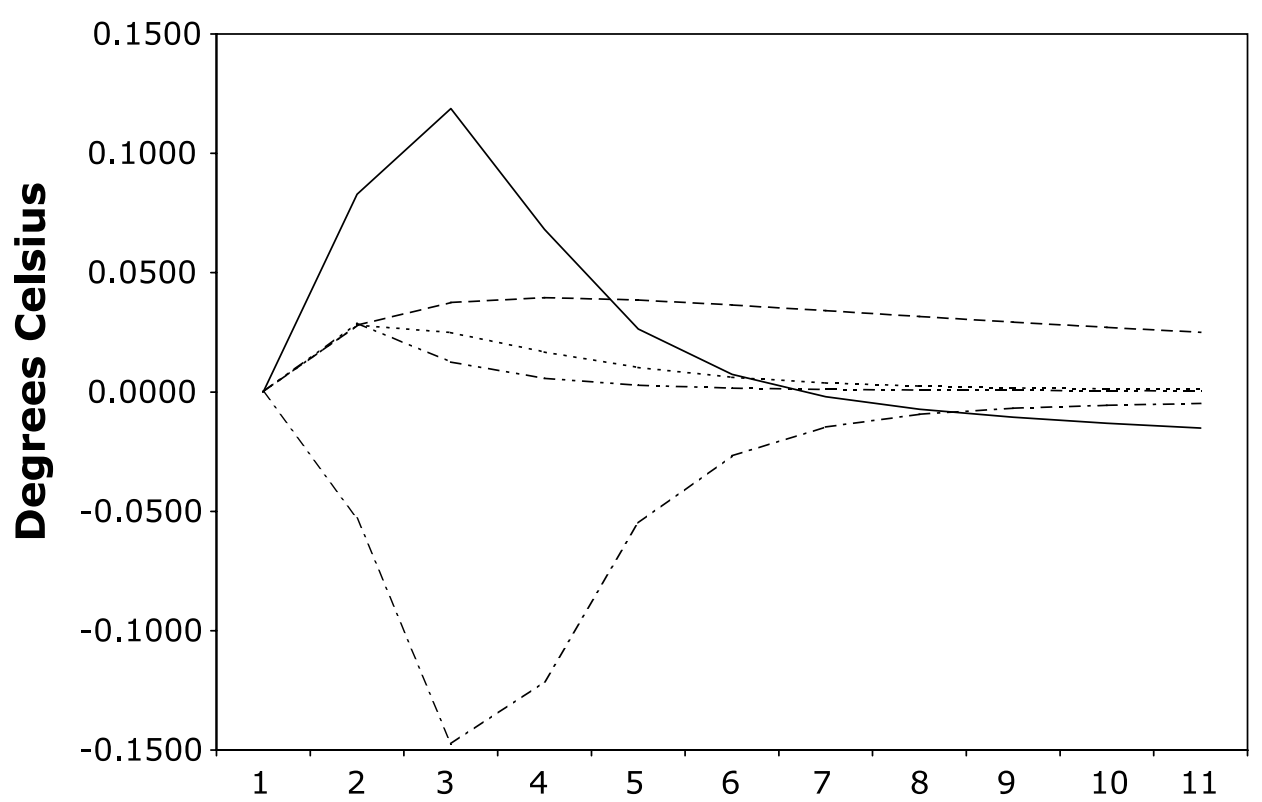

Figure 2. The temperature effects of the $\mathrm{CO}_{2}$ experiment (long dashed line), the $\mathrm{CH}_{4}$ experiment (dotted line), the sun experiment (short dashed line), the ENSO experiment (solid line), and the Pinatubo experiment (dashed doted line).

persistence of $\mathrm{CH}_{4}$ in the atmosphere. As described earlier, the persistence of this effect probably is too short because the $\mathrm{CH}_{4}$ equation underestimates the atmospheric residence time of methane. Because the atmospheric lifetime of $\mathrm{CO}_{2}$ is significantly longer than the rate at which temperature adjusts to the increase in radiative forcing, temperature continues to rise beyond the immediate effect. Nonetheless, this effect also fades over time. Consistent with the statistical difficulties associated with estimating $\rho$ for the $\mathrm{CO}_{2}$ equation, the length of this period cannot be determined with much certainty.

The impulse response functions indicate that the El Niño-Southern Oscillation has a significant effect on global surface temperature and atmospheric $\mathrm{CO}_{2}$. Values for the SOI which simulate the 1982-1983 El Niño event increase global surface temperature by about $0.1^{\circ} \mathrm{C}$ (Figure 2). This effect is slightly lower than previous estimates of about $0.2^{\circ} \mathrm{C}$ (Jones, 1989; Angell, 1988). This temperature increase is not large enough to offset completely the effect of the SOI variable in the $\mathrm{CO}_{2}$ equation therefore, the ENSO experiment indicates that on net, the 1982-1983 El Niño reduced atmospheric $\mathrm{CO}_{2}$ by about $0.34 \mathrm{ppmv}$. This negative effect is consistent with analyses that suggest that ENSO events reduce the flow of carbon to the atmosphere by slowing ocean upwelling (Dettinger and Ghil, 1998; Winguth et al., 1998) or that enhanced incoming solar radiation during the early stages of an ENSO event increase carbon uptake by terrestrial vegetation (Graham et al., 2003; Yang and Wang, 2000). This reduction also is consistent with an inverse 
relation between ENSO and the atmospheric growth rate of $\mathrm{CO}_{2}$ (Rayner et al., 1999; Francey et al., 1995). Conversely, the net negative effect seems to contradict results that indicate atmospheric concentrations of $\mathrm{CO}_{2}$ rise during ENSO events because reduced uptake by the terrestrial biota exceeds the increased uptake by the oceans (Joos et al., 1995; Keeling et al., 1995).

Consistent with the uncertainty about the temperature effect of volcanic activity described above, estimates for the temperature effect of the Mount Pinatubo eruption vary. The Pinatubo experiment indicates that this eruption reduced annual global surface temperature by a maximum of $-0.12^{\circ} \mathrm{C}$ (Figure 2). This effect is similar to the two year reduction $\left(-0.19\right.$ and $\left.-0.18^{\circ} \mathrm{C}\right)$ found by Yang and Schlesinger (2001) after they removed the temperature effects of the concurrent El Niño-Southern Oscillation. Both of these effects are slightly smaller than the temperature effects generated by Hansen et al. (1992). Together, these results imply that our statistical estimate cannot be used to narrow the existing range for the temperature effect of stratospheric sulfates. Nonetheless, the statistical estimate for the temperature effect of stratospheric sulfates is not unreasonable and does not undermine the estimate for the temperature effect of greenhouse gases, anthropogenic sulfur emissions, and solar irradiance.

\subsection{TEMPERATURE SENSITIVITY AND TEMPERATURE DYNAMICS}

The estimates for $\beta_{1}$ in Equation (3) and $\beta_{2}$ in Equation (4) can be used to evaluate the temperature sensitivity and dynamics of the climate system. The DOLS estimate of $\beta_{1}$ reported in column 2 of Table II (0.489) indicates that doubling the pre-industrial concentration of $\mathrm{CO}_{2}$ would increase global surface temperature by about $2.1^{\circ} \mathrm{C}$ $(0.489 \times 6.3 \times \ln (2))$, with a $95 \%$ confidence interval of 1.8 to $2.5^{\circ} \mathrm{C}$ based on the more conservative Newey-West standard errors in Table II.

This estimate begs the question regarding the time scale of the change. These adjustments are summarized by three definitions of temperature sensitivity: the transient climate response, the equilibrium climate sensitivity, and the effective climate sensitivity (Cubasch and Meehl, 2001). Analysis of simulations run for the coupled models intercomparison project indicate that the temperature effect of doubled $\mathrm{CO}_{2}$ estimated here is consistent with the transient climate response (Kaufmann et al., 2006).

Consistent with this interpretation, the temperature sensitivity implied by $\beta_{1}$ $2.1{ }^{\circ} \mathrm{C}$ falls in the middle of the 1.2 to $3.1^{\circ} \mathrm{C}$ range of values for the transient climate response simulated by climate models (Cubasch and Meehl, 2001). This range can be narrowed by our estimate for $\beta_{1}$. Using the Newey West estimator, which generates larger standard errors than the VARHAC estimator, the 95 percent confidence interval for our statistical estimate of $\beta_{1}$ is equivalent to a temperature sensitivity of $1.8-2.5^{\circ} \mathrm{C}$. This range does not vary greatly by period. The DOLS estimate for $\beta_{1}$ with data for 1900-1991 (the more reliable portion of the temperature 
data), yields a 95 percent confidence interval of $1.9-2.8^{\circ} \mathrm{C}$ while data for 1959 1991 (the start date for the Mauna Loa record for atmospheric $\mathrm{CO}_{2}$ measurements) yields a range of $1.4-2.4{ }^{\circ} \mathrm{C}$.

The rapid rate of adjustment represent by $\beta_{2}$ also is consistent with the rates of adjustment associated with the transient climate response. Simulating the CMIP2 experiments analyzed by Kaufmann et al. (2006) (an annual one percent increase in atmospheric $\mathrm{CO}_{2}$ until concentration doubles) with Equations (13)-(22) indicates that about 95 percent of the temperature increase implied by $\beta_{1}$ occurs at the time that the atmospheric concentration of $\mathrm{CO}_{2}$ doubles. This rapid rate of adjustment and sharp slowdown thereafter is consistent with the abrupt slow-down in the temperature increase simulated by the CMIP2 experiments that occurs immediately after the initial doubling of the atmospheric concentration of $\mathrm{CO}_{2}$.

\section{Conclusion}

Recent advances in time series econometrics can be used to estimate statistically meaningful equations for the relation among human activities that emit $\mathrm{CO}_{2}$ and $\mathrm{CH}_{4}$, the atmospheric concentration of these gases, and global surface temperature. The results provide direct evidence that there is a statistically meaningful relationship between global surface temperature and an aggregate of radiative forcing that includes greenhouse gases, anthropogenic sulfur emissions, and solar activity. A simple model based on these results indicates that greenhouse gases and anthropogenic sulfur emissions are largely responsible for the observed increase in global surface temperature between 1870 and 1990. This result is direct evidence for the effect of human activity and global climate.

The effect of human activity on surface temperature is reinforced by the simultaneous relationship between surface temperature and the atmospheric concentration of $\mathrm{CO}_{2}$. Our results indicate that the global carbon cycle contains a positive feedback loop in which temperature increases associated with human activities that emit $\mathrm{CO}_{2}$ (and other greenhouse gases) change flows to and from the atmosphere in a way that on net increases the atmospheric concentrations of $\mathrm{CO}_{2}$, increases its radiative forcing, and increases temperature further. Together, our estimates for the simultaneous linkages among climate, human activity, and the biogeochemical cycling of carbon improve empirical estimates that focus on individual links and omit important variables.

\section{References}

Albritton, D. L. and Meira Filho, L. G.: 2001, 'Technical summary', in: Houghton et al. (eds.), Climate Change 2001: The Scientific Basis. Cambridge University Press, New York.

Allen, R. J., Nicholls, N., Jones, P. D. and Butterworth, I. J.: 1991, 'A further extension of the TahitiDarwin SOI, early SOI results and Darwin pressure', J. Clim. 4, 743-749. 
Anderson, T. W.: 2005, 'Origins of the limited information maximum likelihood and two-stage least sqaure estimators', J. Econ. 12(1), 1-16.

Anderson, T. W. and Rubin, H.: 1949, 'Estimation of the parameters of a single equation in a complete system of stochastic equations', Annal. Math. Stat. 20, 46-63.

Andronova, N. G. and Schlesinger, M. E.: 2000, 'Causes of global temperature changes during the 19th and 20th century', Geophys. Res. Lett. 27, 2137-2140.

Angell, J. K.: 1988, 'Impact of El Niño on the delineation of tropospheric cooling due to volcanic eruptions', J. Geophys. Res. 93, 3697-3704.

A. S. L. and Associates, Sulfur Emissions By Country And Year, Report No: DE96014790, US Department of Energy, Washington DC, 1997.

Bacastow, R. B.: 1976, 'Modulation of atmospheric carbon dioxide by the southern oscillation', Nature 261, 116-118.

Craig, S., Holmen, K., and Bjorkstrom, A.: 1997, 'Net terrestrial carbon exchange from mass balance calculations: an uncertainty estimate', Tellus 49B, 136-148.

Cubash, U. and Meehl, G. A.: 2001, 'Projections of future climate change, in: Houghton et al. (eds.), Climate Change 2001: The Scientific Basis. Cambridge University Press, New York.

Dickey, D. A. and Fuller, W. A.: 1979, 'Distribution of the estimators for autoregressive time series with a unit root', J. Am. Stat. Assoc. 74, 427-431.

Dettinger, M. D. and Ghil, M.: 1998, 'Seasonal and interannual variations of atmospheric $\mathrm{CO}_{2}$ and climate', Tellus 50B, 1-24.

Dlugokencky, E. J., Lang, P. M., Masarie, K. A. and Steele, L. P.: 1994, 'Global CH4 record from the NOAA/CMDL air sampling network', in: Boden, T. A., Kaiser, D. P., Sepanski, R. J., and Stoss, F. S. (eds.), Trends '93: A Compendium of Data on Global Change, ORNL/CDIAC-65, Carbon Dioxide Information Analysis Center, Oak Ridge National Laboratory, Oak Ridge TN, pp. 262-266.

Ehhalt, D. and Prather, M.: 2001, 'Atmospheric chemistry and greenhouse gases', in: Houghton et al. (eds.), Climate Change 2001: The Scientific Basis. Cambridge University Press, New York.

Elkins, J. W., et al.: 1994, 'Global and hemispheric means of CFC-11 and CFC-12 from the NOAA/CMDL flask sampling program', in: Boden, T. A., Kaiser, D. P., Sepanski, R. J. and Stoss, F. S. (eds.), Trends '93: A Compendium of Data on Global Change, ORNL/CDIAC-65, Carbon Dioxide Information Analysis Center, Oak Ridge National Laboratory, Oak Ridge TN, pp. 501-504.

Engle, R. F. and Granger, C. W. J.: 1987, 'Co-integration and error correction: Representation, estimation, and testing', Econometrica 55, 251-276.

Etheridge D. M., Pearman, G. I., and Fraser, P. J.: 1994, 'Historical $\mathrm{CH}_{4}$ record from the "DE08" ice core at Law Dome', in: Boden, T. A., Kaiser, D. P., Sepanski, R. J., and Stoss, F. S. (eds.), Trends '93: A Compendium of Data on Global Change, ORNL/CDIAC-65, Carbon Dioxide Information Analysis Center, Oak Ridge National Laboratory, Oak Ridge TN, pp. 256-260.

Etheridge, D. M., Steele, L. P., Langenfelds, L. P., and Francey, R. J.: 1996, 'Natural and anthropogenic changes in atmospheric $\mathrm{CO}_{2}$ over the last 1000 years from air in Antarctic ice and firn', J. Geophys. Res. 101, 4115-4128.

Folland, C. K., et al.: 1992, 'Observed climate variability and change', in: Houghton, J. T., Callander, B. A. and Varney, S. K. (eds.), Climate Change 1992: The Supplementary Report to the IPCC Scientific Assessment, Cambridge University Press, Cambridge.

Francey, R. J., et al.: 1995, 'Changes in oceanic and terrestrial carbon uptake since 1982', Nature 373, $326-330$.

Friedli, H., et al.: 1986, 'Ice core record of the ${ }^{13} \mathrm{C} /{ }^{12} \mathrm{C}$ ratio of atmospheric $\mathrm{CO}_{2}$ in the past two centuries', Nature 324, 237-238.

Goulden, et al.: 1998, 'Sensitivity of boreal forest carbon balance to soil thaw', Science 279, 214 217. 
Graham, E. A., Mulkey, S. S., Kitajima, K., Phillips, N. G., and Wright, S. J.: 2003, 'Cloud cover limits net $\mathrm{CO}_{2}$ uptake and growth of a rainforest tree during tropical rainy seasons', PNAS 100, 572-576.

Granger, C. W. J. and Newbold, P.: 1974, 'Spurious regressions in econometrics', J. Econ. 2, 111-120.

Hamilton, J. D.: 1994, Time Series Analysis, Princeton University Press, Princeton NJ.

Hansen, J., Lacis, A., Ruedy, R., and Sato, M.: 1992, 'Potential climate impact of Mount Pinatubo eruption', Geophys. Res. Lett. 19, 215-218.

Houghton, R. A. and Hackler, J. L.: 1999, 'Continental Scale Estimates of the Biotic Carbon Flux from Land Cover Change: 1850 to 1980', CDIAC Data Set.

Houghton, R. A., Davidson, E. A. and Woodwell, G. M.: 1998, 'Missing sinks, feedbacks, and understanding the role of terrestrial ecosystems in the global carbon balance', Global Biogeochem. Cycles 12, 25-34.

Hurrell, J. W.: 1996, 'Influence of variations in extratropical wintertime teleconnections on northern hemisphere temperature', Geophys. Res. Lett. 23, 665-668.

Hurrell, J. W.: 1995, 'Decadal trends in the North Atlantic oscillation: Regional temperature and precipitation', Science 269, 676-679.

Jones, P. D.: 1994, 'Estimating sampling error in large scale temperature averages', J. Clim. 7, 1794 1802.

Jones, P. D.: 1989, 'The influence of ENSO on global temperatures', Clim. Monit. 17, 80-89.

Joos, F., et al.: 1999, 'The variability in the carbon sinks as reconstructed for the last 1000 years', Geophys. Res. Lett. 26, 1437-1440.

Hamilton, J. D.: 1994, Time Series Analysis. Princeton University Press, Princeton.

Kattenberg, A. F., et al.: 1996, 'Climate models - projections of future climate', in: Houghton, J. T., Meira Filho, L. G., Callander, B. A., Harris, N., Kattenberg, A. and Maskell, K. (eds.), Climate Change 1995: The Science of Climate Change. Cambridge University Press, Cambridge.

Kaufmann, R. K., Kauppi, H., and Stock, J. H.: 2006, 'The relation ebtween radiative forcing and temperature: What do statistical analyses of the observational record measure?', Clim. Change, current issue.

Kaufmann, R. K. and Stern, D. I.: 1997, 'Evidence for human influence on climate from hemispheric temperature relations', Nature 388, 39-44.

Kaufmann, R. K. and Stern, D. I.: 2002, 'Cointegration analysis of hemispheric temperature relations', J. Geophys. Res. 107, D2 10.1029, $2000 J D 000174$.

Kaufmann, R. K. and Stock, J. H.: 2003, 'Testing hypotheses about the mechanisms for the unknown carbon sink: A time series analysis', Global Biogeochem. Cycles 17(2), 1072 doi:10.1029/2002GB001962.

Kauppi, H.: 2004, 'On the robustness of hypothesis testing based on fully modified vector autoregression when some roots are almost one', Econ. Theor. 20, 341-359.

Keeling, C. D.: 1973, 'Industrial production of carbon dioxide from fossil fuels and limestone', Tellus 25, 174-198.

Keeling C. D. and Whorf, T. P.: 1994, 'Atmospheric $\mathrm{CO}_{2}$ records from sites in the SIO air sampling network', in: Boden, T. A., Kaiser, D. P., Sepanski, R. J. and Stoss, F. S. (eds.), Trends '93: A Compendium of Data on Global Change, ORNL/CDIAC-65, Carbon Dioxide Information Analysis Center, Oak Ridge National Laboratory, Oak Ridge TN, pp. 16-26.

Keeling, C. D., Whorf, T. P., Whalen, M., van der Plicht, J.: 1995, 'Interannual extremes in the rate of rise of atmospheric carbon dioxide since 1980', Nature 375, 666-670.

Keeling, C. D., et al.: 1989, 'A three-dimensional model of atmospheric $\mathrm{CO}_{2}$ transport based on observed winds 1, Analysis of observational data, in Aspects of Climate variability in the Pacific and Western Americas', Geophys. Monogr. Ser. 55, 165-236.

Khalil, M. A. K. and Rasmussen, R. A.: 1994, 'Global emissions of methane during the last several centuries', Chemosphere 29, 833-842. 
Krakauer, N. Y. and Randerson, J. T.: 2003, 'Do volcanic eruptions enhance or diminish net primary production? Evidence from tree rings', Global Biogeochem. Cycles 17(4), 10.1029/2003GB002076.

Lean, J., Beer, J. and Bradley, R.: 1995, 'Reconstruction of solar irradiance since 1610: Implications for climate change', Geophys. Res. Lett. 22, 3195-3198.

Lindzen, R. S. and Giannitsis, C.: 1998, 'On the climatic implications of volcanic cooling', J. Geophys. Res. 103, 5929-5941.

MacIntyre, F.: 1978, 'On the temperature coefficient of $P_{\mathrm{CO}_{2}}$ in seawater', Clim. Change 1, 349-354.

MacKinnon, J. G.: 1994, 'Approximate asymptotic distribution functions for unit-root and cointegration tests', J. Bus. Econ. Stat. 12, 167-176.

Marland, G. and Rotty, R. M.: 1984, 'Carbon dioxide emissions from fossil fuels: A procedure for estimation and results for 1950-1982', Tellus 36B, 232-261.

Meehl, G. A., Boer, G. J., Covey, C., Latif, M., and Stouffer, R. J.: 2000, 'The coupled model intercomparison project (CMIP)', Bull. Am. Met. Soc. 81, 313-318.

Mitchell, J. F. B., Johns, T. C., Gregory, J. M., and Tett, S. F. B.: 1995, 'Climate response to increasing levels of greenhouse gases and sulfate aerosols', Nature 376, 501-504.

Mitchell, J. F. B. and Karoly, D. J.: 2001, 'Detection of climate change and attribution of causes', in: Houghton et al. (eds.), Climate Change 2001: The Scientific Basis. Cambridge University Press. New York.

Newey, W. K. and West, K. D.: 1987, 'A simple, positive semi-definite, heteroskedasticity and autocorrelation consistent covariance matrix', Econometrica 55, 703-708.

Nicholls, N., et al.: 1996, 'Observed climate variability and change', in: Houghton, et al. (eds.), Climate Change 1995: The Science of Climate Change. Cambridge University Press, pp. 138-192.

Parker, D. E., Jones, P. D., Folland, C. K., and Bevan, A.: 1994, 'Interdecadal changes of surface temperature since the late 19th century', J. Geophys. Res. 99, 14373-14399.

Phillips, P. C. B. and Ouliaris, S.: 1990, 'Asymptotic properties of residual based tests for cointegration', Econometrica 58, 190.

Prather M., McElroy, M., Wofsy, S., Russel, G., and Rind, D.: 1987, 'Chemistry of the global troposphere: fluorocarbons as tracers of air motion', J. Geophys. Res. 92D, 6579-6613.

Prinn, R., et al.: 1990, 'Atmospheric emissions and trends of nitrous oxide deduced from ten years of ALE/GAUGE data', J. Geophys. Res. 95, 18369-18385.

Prinn, R., et al.: 1995, CDIAC world Data Center dataset no. DB-1001.

Rayner, P. J., Law, R. M., and Dargaville, R.: 1999, 'The relationship between tropical $\mathrm{CO}_{2}$ fluxes and the El-Nino-Southern Oscillation', Geophys. Res. Lett. 26, 493-496.

Santer, B. D., et al.: 1996, 'A search for human influences on the thermal structure of the atmosphere', Nature 382, 39-46.

Sato, M., Hansen, J. E., McCormick, M. P., and Pollack, J. B.: 1993, 'Stratospheric aerosol optical depths, 1850-1990', J. Geophys. Res. 98, 22987-22994.

Schimel, D. S., et al.: 2001, 'Recent patterns and mechanisms of carbon exchange by terrestrial ecosystems', Nature 414, 169-172.

Schwarz, G.: 1978, 'Estimating the dimension of a model', Annal. Stat. 6, 461-464.

Shine, K. P. R. G., Derwent, D. J., Wuebbles, D. J., and Mocrette, J. J.: 1991, 'Radiative forcing of climate', in: Houghton, J. T., Jenkins, G. J. and Ephramus, J. J. (eds.), Climate Change: The IPCC Scientific Assessment, Cambridge University Press, pp. 47-68.

Staiger, D. and Stock, J. H.: 1997, 'Instrumental variables regression with weak instruments', Econometrica $65,557-586$.

Stern D. I. and Kaufmann, R. K.: 2000, 'Detecting a global warming signal in hemispheric temperature series: a structural time series analysis', Climatic Change 47, 411-438.

Stern, D. I. and Kaufmann, R. K.: 1996, 'Estimates of global anthropogenic methane emissions 1860-1993', Chemosphere 33, 159-176. 
Stock, J. H.: 1987, 'Asymptotic properties of least squares estimators of co-integrating vectors', Econometrica 55, 1035-1056.

Stock, J. H. and Watson, M. W.: 1993, 'A simple estimator of cointegrating vectors in higher order integrated systems', Econometrica 61, 783-820.

Tett, S. F. B., Stott, P. A., Allen, M. R., Ingram, W. J., and Mitchell, J. F. B.: 1999, 'Causes of twentieth-century temperature change near the Earth's surface', Nature 399, 569-572.

Tol, R. S. J. and De Vos, A. F.: 1998, 'A Bayesian statistical analysis of the enhanced greenhouse effect', Climatic Change 38, 87-112.

Vukicevic, T., Braswell, B. H., and Schimel, D.: 2001, 'A diagnostic study of temperature controls on global terrestrial carbon exchange', Tellus 53B, 150-170.

Wigley, T. M. L., Jones, P. D., and Raper, S. C. B.: 1997, 'The observed global warming record: What does it tell us?' Proc. Natl. Acad. Sci. 94, 8314-8320.

Wigley, T. M. L. and Raper, S. C. B.: 1992, 'Implications for climate and sea level of revised IPCC emissions scenarios', Nature 357, 293-300.

Wigley, T. M. L., Smith, R. L., and Santer, B. D.: 1998, 'Anthropogenic influence on the autocorrelation structure of hemispheric mean temperatures', Science 282, 1676-1679.

Wignuth, A. M., Heiman, E. H., Kurz, K. D., Maier-Riemer, E., Mikolajewicz, U., and Segschneider, J.: 1994, 'E Nino-Southern Oscillation related fluctuations of the marine carbon cycle', Global Biogeochem. Cycles 8, 39-63.

Wooldridge, J. M.: 2001, Econometric Analysis of Cross Section and Panel Data. Cambridge: MIT Press.

Yang, F. and Schlesinger, M. E.: 2001, 'Identification and separation of Mount Pinatubo and El NinoSouthern Oscillation land surface temperature anomalies', J. Geophy. Res. 106, 14757-14770.

Yang, X. and Wang, M.: 2000, 'Monsoon ecosystems control on atmospheric $\mathrm{CO}_{2}$ interannual variability: Inferred from a significant positive correlation between year-to-year changes in land precipitation and atmospheric $\mathrm{CO}_{2}$ growth rate', Geophys. Res. Lett. 27, 1671-1674.

(Received 14 June 2004; in revised form 21 November 2005) 